\title{
Enumeration of IgA producing cells by the enzyme linked immunospot (ELISPOT) technique to evaluate sulphasalazine effects in inflammatory arthritides
}

\author{
N Feltelius, S Gudmundsson, L Wennersten, O Sjöberg, R Hällgren, L Klareskog
}

\begin{abstract}
Numbers of IgA producing cells in peripheral blood were determined by the enzyme linked immunospot (ELISPOT) technique in 15 patients with inflammatory arthritides receiving sulphasalazine treatment. The numbers of IgA producing cells decreased significantly after the first three weeks of treatment. In 11 of the patients this decrease persisted, whereas a subsequent increase was seen in the four others; in two of these latter patients this increase coincided with a temporary withdrawal of the sulphasalazine treatment. A reduction of serum concentrations of IgA and haptoglobin was seen after three months' treatment. Eleven of the patients had a subjective improvement in their joint disease during the first three months of treatment.

Analysis of circulating cells committed for IgA secretion may constitute one way of assessing gut associated immunity indirectly, and the present data suggest that sulphasalazine has a rapid effect on lymphocytes possibly originating from the gut and that such an effect precedes improvement in laboratory parameters and clinical symptoms in arthritic diseases.
\end{abstract}

The proposed role for the gut and mucosal immune defence mechanisms in inflammatory arthritides has been studied in various ways. In rheumatoid arthritis and ankylosing spondylitis serological, bacteriological, histopathological, and radioisotope methods have provided substantial but not unequivocal support for the role of the gut in inflammatory arthritides. ${ }^{1-4}$ Persistently raised serum concentrations of IgA have been interpreted as signs of stimulation of the secretory immune system, perhaps through the gastrointestinal tract. $^{5}$ Other findings that might support a role for IgA in inflammatory arthritides are IgA deposition in dermal vessels of patients with ankylosing spondylitis at biopsy ${ }^{6}$ and circulating IgA containing immune complexes in patients with ankylosing spondylitis with haematuria. ${ }^{7}$

The clinical efficacy of sulphasalazine in ankylosing spondylitis and rheumatoid arthritis is by now well reported. ${ }^{8} 9$ Serum concentrations of IgA have been shown to decrease in patients with rheumatoid arthritis during successful treatment with sulphasalazine, when measured after three to six months. ${ }^{10}{ }^{11}$ Its mode of action in these diseases is, however, still not clear. The exact time of onset for its immunomodulatory or anti-inflammatory effects in not known, nor to what extent the results are due to local effects of sulphasalazine in the intestine or to more systemic effects of the intact drug or its metabolites. One key question in this context is whether the decreased serum concentrations of IgA seen during sulphasalazine treatment reflect a decreased production of $\operatorname{IgA}$ in the mucosa; most serum IgA is known to originate from cells in the bone marrow. ${ }^{12}$ Another question is whether the change in serum IgA and a putative change in mucosal IgA production occurs early or late after starting sulphasalazine treatment; an early change would imply that the effects on $\operatorname{IgA}$ may be of primary importance for the drug effects on disease activity, a late change would rather indicate that the effects on $\operatorname{IgA}$ are probably secondary to changes in disease activity.

In this study, in an attempt to answer these questions, we used the enzyme linked immunospot (ELISPOT) technique to enumerate IgA producing cells in the circulation in parallel with measurement of serum IgA concentrations before and during sulphasalazine treatment in patients with ankylosing spondylitis and rheumatoid arthritis. IgA producing cells were enumerated because most such cells, in contrast with serum IgA, seem to originate from the mucosa ${ }^{13}$; thus circulating IgA producing cells can be assumed to mirror mucosal IgA production differently and perhaps better than serum IgA concentrations.

Patients and methods

PATIENTS, CLINICAL EVALUATION, AND ROUTINE LABORATORY TESTING

Fifteen outpatients with inflammatory arthritides were studied: two with rheumatoid arthritis according to the American Rheumatism Association criteria, ${ }^{14}$ nine with ankylosing spondylitis according to the New York criteria, ${ }^{15}$ and four with psoriatic arthritis or other seronegative arthritis. Thirty two healthy blood donors served as controls. Patients were selected for treatment with sulphasalazine on the basis of insufficient control of clinical symptoms by non-steroidal anti-inflammatory drugs (NSAIDs). The dose of sulphasalazine given was gradually increased to a final dose of $2.3 \mathrm{~g}$ daily. 8 Most patients continued to receive NSAIDs throughout the study. Clinical evaluation was made before treatment and after three months' treatment with sulphasalazine by estimation of the number of actively inflamed joints, morning stiffness (minutes), and reduction of NSAID consumption in patients with rheumatoid arthritis, and in patients with ankylosing spondylitis Schober's test, chest expansion, and the presence of sacroiliac pain were evaluated additionally. ${ }^{16}$ When improve-

$S$ Gudmundsson

O Sjöberg

Correspondence to:

Dr Feltelius.

Accepted for publication

16 May 1990 
ment was found in more than half of the variables studied the patient was considered to be clinically improved. Laboratory tests were performed before treatment and at three, six, and 12 weeks after the onset of treatment with sulphasalazine. Erythrocyte sedimentation rate was read after one hour according to Westergren. Serum concentrations of haptoglobin (normal value $0.3-2.0 \mathrm{~g} / \mathrm{l}), \operatorname{IgA}(0.8-4.0 \mathrm{~g} / \mathrm{l}), \operatorname{IgG}$ $(7 \cdot 0-18 \cdot 0 \mathrm{~g} / \mathrm{l})$, and $\operatorname{IgM}(0 \cdot 4-2 \cdot 75 \mathrm{~g} / \mathrm{l})$ were measured by nephelometry at the department of clinical chemistry of Uppsala University Hospital.

\section{ESTIMATION OF CIRCULATING IgA PRODUCING CELLS WITH ELISPOT}

Peripheral blood lymphocytes were isolated from heparinised blood samples by FicollHypaque separation. Plates for ELISPOT were

Inflammatory parameters before and after sulphasalazine treatment. Results are given as means (SEM)

\begin{tabular}{lcccc}
\hline & $\begin{array}{l}\text { Before } \\
\text { treatment }\end{array}$ & 3 Weeks & 6 Weeks & 12 Weeks \\
\hline Haptoglobin (g/l) & $2 \cdot 9(0 \cdot 3)$ & $2 \cdot 4(0 \cdot 2)^{*}$ & $1 \cdot 9(0 \cdot 2)^{*}$ & $2 \cdot 2(0 \cdot 2)^{*}$ \\
Serum IgA (g/l) & $3 \cdot 2(0 \cdot 4)$ & $3 \cdot 3(0 \cdot 3)$ & $3 \cdot 1(0 \cdot 4)$ & $2 \cdot 8(0 \cdot 3)^{*}$ \\
Serum IgG (g/l) & $13 \cdot 2(1 \cdot 0)$ & $13 \cdot 3(0 \cdot 9)$ & $12 \cdot 8(1 \cdot 0)^{*}$ & $12 \cdot 3(1 \cdot 1)^{* * *}$ \\
Serum IgM (g/) & $1 \cdot 4(0 \cdot 2)$ & $1 \cdot 5(0 \cdot 3)$ & $1 \cdot 6(0 \cdot 4)$ & $1 \cdot 2(0 \cdot 2)$ \\
Mononuclear cells $\left(\times 10^{9} / 1\right)$ & $2 \cdot 2(0 \cdot 2)$ & $2 \cdot 0(0 \cdot 2)$ & $1 \cdot 8(0 \cdot 1)$ & $1 \cdot 9(0 \cdot 2)$ \\
\hline
\end{tabular}

${ }^{*} p<0.01 ;{ }^{* *} p<0.001$; all $p$ values obtained by comparison with values before treatment.

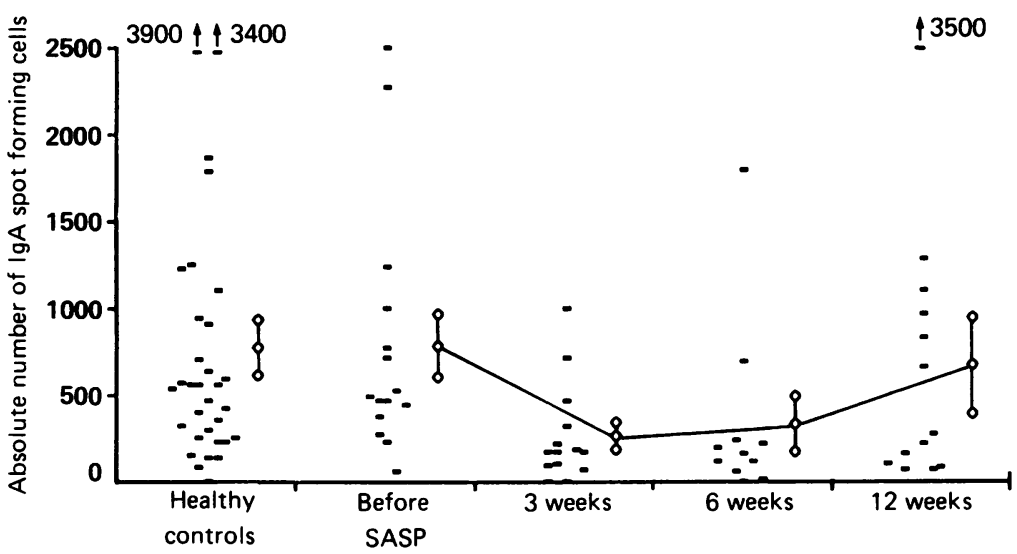

Figure 1 Comparison of the absolute numbers of IgA spot forming cells before sulphasalazine (SASP) treatment and after three, six, and 12 weeks of treatment with Student's t test (paired, two tailed) gave the following results: 3 weeks, $p=0.006 ; 6$ weeks, $p=0 \cdot 065 ; 12$ weeks, $p=0 \cdot 18$.

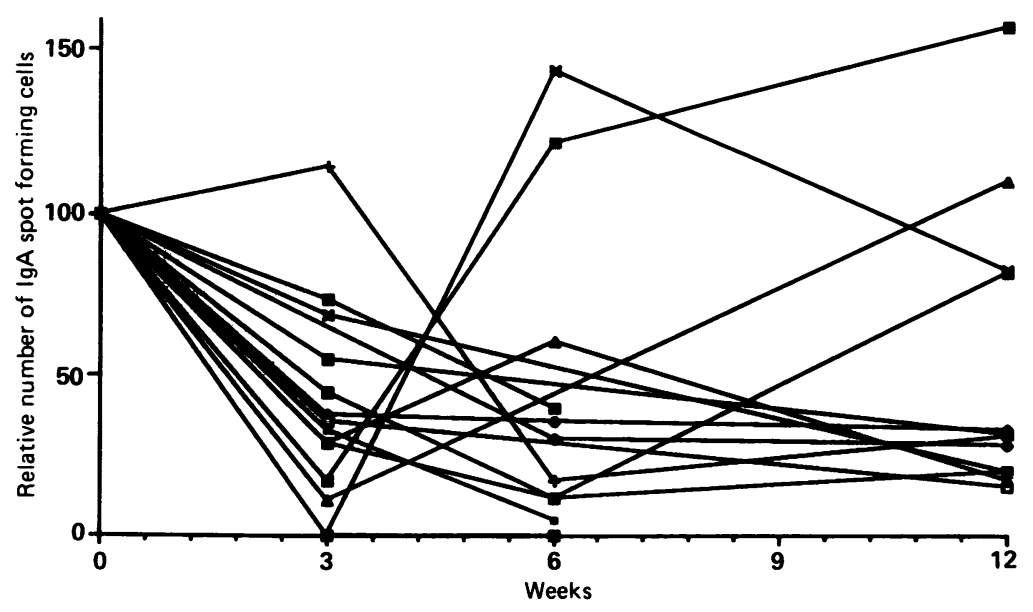

Figure 2 The mean (SEM) relative number of IgA spot forming cells was at three weeks $39 \cdot 4(8 \cdot 4) ; p=0.0001$; at six weeks 43.7 (14.5), $p=0.003$; and at 12 weeks 52.4 (13.2), $p=0.004$; with the value before treatment set at 100 prepared by incubating the upper part of Costar culture plates (with a well diameter of $1.5 \mathrm{~cm}$ ) with affinity purified goat antibodies to human IgA (Jackson) or with rabbit anti-IgA and antiIgM antibodies (Dakopatts), followed by inactivation of unbound plastic sites by $2 \%$ fetal calf serum. The cells were incubated on these wells for three hours at $37^{\circ} \mathrm{C}$ at a concentration of $2 \times 10^{6} \mathrm{cells} / \mathrm{ml}(200 \mu \mathrm{l} / \mathrm{well})$. After washing, the wells were incubated with peroxidase conjugated antihuman IgA antibodies (Dakopatts) overnight at $4^{\circ} \mathrm{C}$. Visualisation of bound antibodies and enumeration of spots was essentially as previously described. ${ }^{17}$ The numbers of spot forming cells were expressed as numbers of IgA producing cells $/ 10^{6}$ mononuclear cells. To compare the effect of sulphasalazine on IgA production over time in different patients we set the index value at the beginning of treatment to 100 in each patient, and thereafter calculated relative changes in numbers of spot forming cells per volume, thus taking the number of mononuclear cells into account.

\section{STATISTICS}

Student's paired $t$ test was used to compare values before and after treatment unless otherwise stated.

\section{Results}

The table summarises the results of the laboratory investigations carried out at $0,3,6$, and 12 weeks after the start of sulphasalazine treatment. The serum concentrations of IgA and IgG were significantly reduced during sulphasalazine treatment when weeks 0 to 12 were compared. Serum haptoglobin concentrations also decreased significantly even after only three weeks. A slight but non-significant reduction of the erythrocyte sedimentation rate was seen. In the clinical evaluation 11 of the 15 patients were considered better - that is, more than half of the clinical variables studied after 12 weeks of sulphasalazine treatment had improved.

Absolute as well as relative numbers of $\operatorname{IgA}$ spot forming cells were determined. Figure 1 shows the absolute numbers of IgA spot forming cells in controls and patients during sulphasalazine treatment. Before the start of treatment no difference was seen between patients and controls (Mann-Whitney U test). After three weeks of sulphasalazine treatment the number of IgA producing cells was significantly reduced compared with the values before treatment, a reduction which persisted almost unaltered at six weeks.

Figure 2 shows the number of IgA producing cells related to the numbers of mononuclear cells for individual patients. A marked decrease in spot forming cells was seen in all cases but one between the first and second points of analysis $(p<0.001)$ after adjustment for the number of mononuclear cells. No such change was seen for IgM producing cells (data not shown). In 11 of the patients this decrease persisted, whereas a return to the initial values was seen in the other four. In two of these patients this augmentation in IgA producing cells coincided with a temporary withdrawal of the drug (less than one week) on the patient's 
own initiative. One of then-with the diagnosis reactive arthritis and with a flare up of urethritis-was treated with antibiotics during this withdrawal. Sulphasalazine had a poor clinical effect in both these patients after three months.

\section{Discussion}

This study is concerned with the regulation of IgA production in patients with inflammatory joint disease and the influence of sulphasalazine treatment. Estimation of numbers of IgA spot forming cells in peripheral blood was chosen as the main variable of the study on the basis of evidence that a large proportion of circulating IgA committed B lymphocytes may indeed originate from secretory sites, mainly the gut. ${ }^{13}$ The idea was to investigate the possibility that potential local effects of sulphasalazine in the gut might be reflected as changes in the outflow of these cells from the gut.

The results show that a substantial decrease in numbers of IgA producing cells occurred early after onset of sulphasalazine treatment in all the 15 patients with inflammatory arthritides investigated. In most patients this decrease was apparent after only three weeks of sulphasalazine treatment-that is, before clinical improvement has been seen in previous studies. ${ }^{8} 18$ In fact, other authors have suggested that a longer treatment period than three months is needed for a fair evaluation of the drug. ${ }^{11}$ Thus clinically detectable treatment effects are unlikely to have occurred at three weeks after institution of sulphasalazine. Patients and controls show similar numbers of IgA producing cells before treatment, but this does not rule out the possibility that these cells are involved in pathogenetic or therapeutic mechanisms.

Notably, the decrease in serum IgA concentrations that was seen in this and in previous studies $^{10}{ }^{11}$ was not apparent until after a longer sulphasalazine treatment time. This suggests that different mechanisms are responsible for the sulphasalazine dependent effects on circulating IgA producing cells and serum concentrations of IgA respectively; the half life of serum IgA is only about four days, ${ }^{19}$ excluding slow clearance of the serum pool of $\operatorname{IgA}$ as a reason for the slow effects on serum IgA concentrations. Interestingly, most serum IgA seems to derive from IgA producing cells in the bone marrow, whereas the circulating IgA producing cells mainly originate from mucosal sites-that is, to a large extent from the intestine. ${ }^{13}$ Against this background it is tempting to suggest that the rapid effect of sulphasalazine on numbers of circulating IgA producing cells should be due to effects of sulphasalazine in the intestine, whereas the slower effects on serum IgA may be due to systemic effects on bone marrow cells, effects that may even be secondary to a general decrease in inflammatory activity in the body.

Our findings suggest that sulphasalazine produces its effects on numbers of circulating IgA producing cells by a local effect in the intestine. Such an effect could obviously be due both to direct action of sulphasalazine on the production and export of IgA producing cells in the intestine or occur indirectly after primary effects of sulphasalazine on the gastrointestinal bacterial flora.

One possibility is that sulphasalazine, present in high concentrations in the intestine, exerts a local immunosuppressive effect on $T$ cells regulating IgA committed cells or acts directly on IgA producing $B$ cells, as described in vitro for antibody production at these concentrations of the drug. ${ }^{20}$ If this were the case the early effects of sulphasalazine on IgA production shown in this study would also be indirect evidence that immunological events occurring in the gastrointestinal tract may precede improvement of arthritis. If confirmed, this method of enumerating and, possibly, determining specificities of circulating IgA producing cells may be useful in further studies both on the mode of action of sulphasalazine in arthritis and on the potential role of mucosal immunity in rheumatoid arthritis and ankylosing spondylitis.

We thank Dr Andrej Tarkowski for valuable discussion of this work. The study was supported by funds from the Swedish Medical Research Council and King Gustaf V's 80 year foundation.

1 Trull A, Ebringer A, Panayi G, Ebringer R, James D C O. HLA-B27 and the immune response to enterobacterial antigens in ankylosing spondylitis. Clin Exp Immunol 1984; 55: 74-80.

2 Ebringer $R$ W, Cawdell D R, Cowling P, Ebringer A. Sequential studies in ankylosing spondylitis: association of klebsiella pneumonia with active disease. Ann Rheum Dis 1978; 37: 146-51.

3 Cuvelier C, Barbatis C, Mielants H, De Vos M, Roels H, Veys E. Histopathology of intestinal inflammation related to reactive arthritis. Gut 1987; 28: 394-410.

4 Segal A W, Isenberg D A, Hajirrousou V, Tolfree S, Clarc J, Snaith M L. Preliminary evidence for gut involvement in the pathogenesis of rheumatoid arthritis. Br $\mathcal{J}$ Rheumatol 1986; 25: 162-70.

5 Cowling P, Ebringer R, Ebringer A. Association of inflammation with raised serum IgA in ankylosing spondylitis. Ann Rheum Dis 1980; 39: 545-9.

6 Collado A, Sanmarti R, Bielsa I, et al. Immunoglobulin A in the skin of patients with ankylosing spondylitis. Ann Rherom Dis 1988; 47: 1004-7.

7 Peeters A J, van den Wall Bake A W, van Dalsen A D, Westedt M-L. Relation of microscopic haematuria in ankylosing spondylitis to circulating IgA containing immune complexes. Ann Rheum Dis 1988; 47: 645-7.

8 Feltelius N, Hälgren R. Sulphasalazine in ankylosing spondylitis. Ann Rheum Dis 1986; 45: 396-9.

9 Box D E, Amos R S, Sulphasalazine: a safe, effective agent for prolonged control of rheumatoid arthritis: a comparison with sodium aurothiomalate. Ann Rheum Dis 1985; 44: $194-8$.

10 Feltelius $N$, Hällgren $R$, Sjöberg $O$. $T$ lymphocytes in ankylosing spondylitis and the influence of sulphasalazine treatment. Clin Rheumatol 1987; 6: 545-52.

11 Nissilä M, Lehtinen $K$, Leirisalo-Repo $M$, Luukkainen $R$, Mutru O, Yli-Kerttula U. Sulfasalazine in the treatment of ankylosing spondylitis. Arthritis Rheum 1988; 31: 1111-6.

12 Kutteh W H, Prince S J, Mestecky J. Tissue origins of human polymeric and monomeric IgA. F Immunol 1982; 128: 990.

13 Mestecky J, McGhee J. Immunoglobulin A (IgA): molecular and cellular interactions involved in IgA biosynthesis and immune response. Adv Immunol 1988; 40: 153-245.

14 Arnett F C, Edworthy S M, Bloch D A, et al. The American Rheumatism Association 1987 revised criteria for the classification of rheumatoid arthritis. Arthritis Rheum 1988; 31: 315-24.

15 Bennett P H, Wood P H N. Population studies of the rheumatic diseases. Amsterdam: Excerpta Medica, 1968: 456.

16 Feltelius N, Hällgren R. Circulating inhibitor bound elastase in patients with ankylosing spondylitis and rheumatoid in patients with ankylosing spondylitis and rheumatoid
arthritis, and the influence of sulphasalazine treatment. arthritis, and the influence of supt
Ann Rheum Dis 1988; 47: 10-14.

17 Czerkinsky C, Tarkowski A, Nilsson L-A, Ouchterlony Ö, Nygren H, Gretzer C. Reverse enzyme-linked immunospot Nygren H, Gretzer C. Reverse enzyme-linked immunospot
(RELISPOT) assay for detection of cells secreting immuno(RELISPOT) assay for detection of cells secreting immuno-
reactive substances. F Immunol Methods 1984; 72: 489-96.

18 Dougados $M$, Boumier $P$, Amor $B$. Sulphasalazine in ankylosing spondylitis: a double-blind controlled study in 60 patients. BMF 1986; 293: 911-4.

19 Delacroix D L, Elkom K B, Geubel A P, Hodgson H F, Dire $C$, Vaerman J P. Changes in size, subclass and metabolic properties of serum immunoglobulin $A$ in liver diseases and in other diseases with high serum immunoglobulin A. $f$ Clin Invest 1983; 71: 358-67.

20 Comer S S, Jasin H E. In vitro modulatory effects of sulphasalazine on its metabolites. Arthritis Rheum 1986; 29 (suppl): 79. 